\title{
Sünnituskohaga ei mangita! \\ Skandaalse uudise vastuvõtt Facebooki grupis KalambuuR
}

AIRIKA HARRIK

„Aeg soosib lühivorme,” ütles kalamburist Keiti Vilms kogumiku „Poeetiliselt korrektne" (Juur jt 2019) Tartu esitlusel 2019. aasta aprillis, ning tema üldistaval väitel on tõepõhi all. Vilmsi ning teiste tuntud kalambuuriautorite kõrval tegutseb veebis ka rahvapäraseid sõnamänguhuviliste kogukondi. Käesolevas artiklis keskendun Facebooki grupile KalambuuR, mis on sõnamängukogukondadest suurim ja ilmselt tuntuim. Esmalt annan ülevaate grupist endast, avades selle liikmete käitumismustreid, postituste sisu ning ülesehitust jt iseloomulikke jooni 2018. aasta märtsikuu tegevuse põhjal. Seejärel vaatlen lähemalt ühe konkreetse uudise vastuvõttu grupis, analüüsides Russell Franki (2011) ja Giselinde Kuipersi (2002) uudisfolkloori käsitluste toel KalambuuRi liikmete reaktsioone nn Igor Mangi ahistamisskandaalile 2018. aasta maikuus. ${ }^{1}$

\section{KalambuuRi postitused lingvistilise huumoriteooria valguses}

Sõna kalambuur on eesti keelde laenatud prantsuse keelest, kus calembour tähistab sõnamängu. Eesti folkloristikas pole kalambuuri varem uuritud; erialakirjanduseski kohtab seda vaid mainimise tasandil. Arvo Krikmann (1997: 68) ei pea kalambuuri iseseisvaks folkloorižanriks, kuid tutvustades mõistatuse perifeeriat, nimetab sinna kuuluvatena kalambuurile olemuslikult lähedasi liitsõna- ja tähemänge, nt Missugune pea ei mõtle? - Kapsapea, naelapea vms (Krikmann 1997: 19). Lisaks eelnimetatule on Eesti materjalis varasemast ajast teada veel sõnamängulised värssmõistatused (Eesti värssmõistatused 2015). Ajalooliseltki pole sõnadega mängimine uus nähtus: kalambuure leiab nii heebreakeelsest piiblist (Whedbee 1998), Shakespeare'i teostest kui ka XIX ja XX sajandi vahetuse kirjanike Lewis Carrolli, Charles Dickensi ja James Joyce’i jt töödest (Examples of Puns...).

Käsitletud on teisi keelemängulisi lühivorme ning varem suuliselt ja kirjalikult levinud nähtuste uusi ning sageli digitaalseid vorme. Lähtudes Salvatore Attardost (1994: 141), kes mõistab kalambuure ja keelevääratusi lähedaste nähtustena, on Piret Voolaid analüüsinud lapsesuuütlusi (Voolaid 2015) ning spordikommentaatorite spontaanseid ütlemisi (Voolaid, Voolaid 2020, vt siinses numbris lk 44-61) ehk taht-

${ }^{1}$ Artikkel toetub autori magistritööle „Folkloristlik vaade KalambuuRile Facebookis” (Harrik 2019) ja on selle kolmanda peatüki edasiarendus. 
matuid sõnamänge. Nendes uurimustes toetub ta Attardo (1994: 141) seisukohale, et nii kalambuurid kui ka keelevääratused pakuvad sissevaadet psühholingvistikasse ja häälikuloosse. Anneli Barani lühivormialaste uurimuste keskmes on varasemate nähtuste kajastused uues kontekstis: fraseologismid eesti koolinoorte suhtluses (Baran 2010) ja veebimeedia keeles (Baran 2011), nende visualiseerimine reklaamikunstis (Baran 2013, 2014) ning pildiline netihuumor (Baran 2012).

Kalambuurid on aga viimaste aastate jooksul populaarsust kogunud. Eesti tuntuim kalamburist Keiti Vilms on alates 2014. aastast postitanud Twitteri keskkonda sõnamänge nii oma nime kui ka konto „metsik lingvistika” alt. „Poeetiliselt korrektne” (Juur jt 2019) on „@keitivilmsi” (Vilms 2017) järel juba teine kalambuurikogumik, mille valmimises ta osales. „Poeetiliselt korrektse” üks kaasautoreid Mart Juur juhtis 2018. aasta kirjandusfestivalil HeadRead kalambuuriõhtut (Viilup 2018) ning on põiminud sõnamänge oma teostesse. Nimetada saab teisigi kalambuurikogumikke: Mati Soomre (kirjanikunimega A. Itskok) „Algus on otsas. Keelevigureid” (1998), Andrus Ülviste „Poogen, kopp ja siiber” (2012) ning kunagise huumoriajakirja Pikker rubriigi „Verbaarium” põhjal valminud sõnamängude samanimeline valimik (Veskioja 2018). Tuntud autorite ja kalambuurikogumike kõrval harrastatakse sõnamängu veebikogukondades, millest suurim ja aktiivseim on Facebooki grupp KalambuuR - 2010. aastast tegutsev avalik grupp, millel oli 2019. aasta novembri seisuga umbes 21200 liiget. Grupp pakub laiale ringile keelehuvilistele võimalust postitada sõnamängulisi nalju, et selle kaudu avaldada seisukohti, leida mõttekaaslasi ning tähistada tähtpäevi. Grupis sagedamini postitavatest ning muidu argiselt aktiivsematest kasutajatest on moodustunud mõnekümne liikmega pärimusrühm suure kogukonna sees.

Vastukajaks 2018. aasta maikuus „Pealtnägija” saates eetrisse läinud uudisele Igor Mangist tehti KalambuuRis sama aasta maikuu jooksul 32 selleteemalist postitust. Neid analüüsides keskendun skandaalse uudise vastuvõtule grupis ning rühma liikmete kommentaarides avalduvatele (väärtus)hinnangutele. Postituste autorite nimed olen kodeerinud kujul „Eesnimetäht + Perekonnanimetäht (sugu)”. Esmalt annan aga ülevaate KalambuuRi grupist ja selle postitustest üldisemalt.

Moodustusvõtete alusel jaguneb materjal kõige laiemalt kaheks: sõnalisteks (pesu pesemine on väga rassistlik tegevus, valged eraldatakse värvilistest - KL (m), 26. III) ja pildilisteks (Jutt või asi... - TP (m), 14. III, vt pilt 1) kalambuurideks. Sõnaline kalambuur koosneb vaid sõnadest ning muudest Facebooki pakutavatest tekstilisandustest, nagu emotikonid, taustapildid ja kleepsud. Pildiline kalambuur sisaldab seevastu väljastpoolt Facebooki pärinevat visuaalset materjali, nagu kuvatõmmised, internetist leitud pildid või pildiline omalooming. Igor Mangi juhtumi teemaliste naljade seas on pildilisi postitusi vaid kaks, seevastu 30 sõnalist kalambuuri. Minu varasem uurimuski näitab, et sõnalised naljad on selles grupis valdavas ülekaalus. Nt 2018. aasta märtsi 420 postitusest KalambuuRis olid 333 sõnalised ja 87 pildilised. (Harrik 2019: 21) 


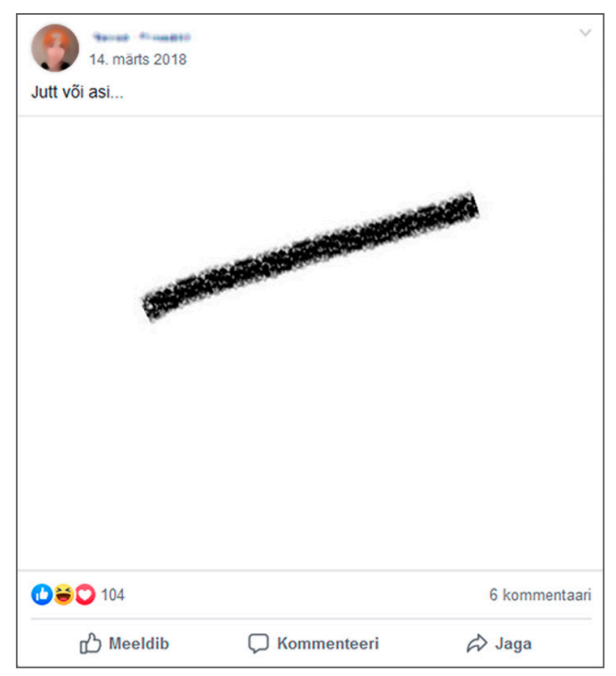

Pilt 1. Jutt või asi...

Täpsemaks moodustusvõttepõhiseks vaatluseks kasutasin Salvatore Attardo ja Victor Raskini (1991; viidatud Attardo 1994 järgi) verbaalse huumori üldteooriat (ingl general theory of verbal humor). Attardo ja Raskin eristavad igas naljatekstis kuut teadmusressurssi: keel, narratiivne strateegia, sihtmärk, situatsioon, loogiline mehhanism ning skriptide opositsioon. Ressursid on järjestatud, pidades silmas nende mõju naljatekstide varieeruvusele: inimene tajub kaht naljateksti sarnasemana, kui need varieeruvad keeletasandil; erinevamana tajutakse aga erineva skriptiopositsiooni ehk puändieelse või -järgse osaga nalju. (Attardo 1994: 228) Mina keskendusin verbaalse huumori üldteooria kahele esimesele ressursile ehk keeletasandile ja narratiivse strateegia tasandile.

Keeletasandil jälgisin kalambuuri postitajate valikuid sõnamoodustuses, sõnastuses ja semantikas. Liigitasin kalambuure kolme leksikaalse suhte alusel: paronüümid ehk sarnassõnad (väga venemeelne inimene ehk rossist - VV (m), 15. III; paronüümia: rossist rassist), polüseemsed ehk mitmetähenduslikud sõnad ( $M a$ olen kleptomaan. Vahetevahel ma võtan selle vastu midagi - RM (m), 23. III; polüseemia: võtma 'võtma ravimit; varastama') ning homonüümid ehk ühtelangevad sõnad (Olin sõbra bemmis täiesti audis - MK (m), 8. III; homonüümia: automark Audi audis 'tegutsemisvõimetu'). Viimane kategooria jaguneb omakorda homofoonideks ehk samakõlalisteks sõnadeks (ülisuurte rindadega naine büstitas maailmarekordi LMK (n), 3. III; homofoonia: büstitas püstitas) ning homograafideks ehk ühtiva kirjapildiga sõnadeks (Must see. - OO (m), 1. III; homograafia: must see ingl 'peab nägema', ee 'see [ese on] räpane'). Materjali vaatlusel ilmnes, et enim mängitakse nii sõnaliste kui ka pildiliste kalambuuride loomisel sarnassõnade (kolmandik sõnalistest ja neljandik pildilistest kalambuuridest) ja mitmetähenduslikkusega (kolmandik nii sõnalistest kui ka pildilistest kalambuuridest). 
Narratiivse strateegia tasandil keskendusin postitaja valikutele kalambuuri lausestuses. Eristasin esmaseid vormistusvõtteid (nt väitlause, sõnastikukirje, uudismõiste, küsimus) ja lisavõtteid (nt kuhjamine, paradoks). Kui iga kalambuur kasutas paratamatult mingit esmast lausevõtet, siis lisavõte - nagu nimigi ütleb - võis esineda mõnes sõnamängus lisaks esmasele võttele. Nii sõnaliste kui ka pildiliste naljade seas oli levinuim narratiivne strateegia esitada kalambuur väitlause kujul (Paksuamet pani paksuvõlglased dieedile - VV (m), 12. III). Üsna sagedasti vormistati nali veel n-ö sõnastikukirjena (Mehetegu - poisslapse eostamine - TK (m), 10. III) või seletuseta uudismõistena (Paavstupüha - ZT (n), 29. III). Lisavõtetest eelistati enim akumulatsiooni ehk mingi sõnastusvõtte kahe- või enamakordset kuhjamist (Kriisipuder, kriisihelbed ja kriisigaletid. Kriisipulgad ka. Kriis kanaga - SV (m)).

Postitustega kaasnevas suhtluses huvitasid mind KalambuuRi liikmeskonna käitumismustrid. Vaadeldud kuu jooksul postitati ühes päevas keskmiselt 13,7 sõnamängu ehk KalambuuR on elujõuline pärimusrühm. (Põgusa vaatluse põhjal tundub see kehtivat ka siinse artikli valmimise ajal, 2020. aasta jaanuaris.) Kolme järjestikuse päeva jooksul liikmete käitumist jälgides selgus aga, et sellel hetkel grupis olnud 17800 liikmest ilmutas argiselt aktiivsust veidi üle 1100 liikme. Kõigil kolmel vaadeldud päeval postitasid või olid muul moel aktiivsed vaid 27 liiget. (Vt Harrik 2019: 61-65) Meessoost liikmed postitasid kolm korda rohkem kui naissoost liikmed: 2018. aasta märtsi 420 postitust olid teinud 317 meessoost ning vaid 103 naissoost kasutajat. Kellaajaliselt postitati kõige enam kalambuure kella kaheksa ja viie vahel päeval ehk tööajal, vähem õhtul kella viiest südaööni ning haruharva öösiti. Tipphetk saabus postitamissageduses kella kahe ja kolme vahel päeval ehk pärast lõunapausi. (Harrik 2019: 43-45)

Analüüsides 2018. aasta märtsi KalambuuRi postituste pälvitud tähelepanu, vaatlesin muuhulgas reaktsioonide ja kommentaaride rohkuse seost postituse vormi ja teemaga: umbes poolte postituste juures jäi tähelepanu tagasihoidlikuks (kuni 24 reaktsiooni) või puudus üldse; üle 100 reaktsiooni pälvis vaid seitsmendik kõigist postitustest. Enim reaktsioone ja kommentaare pälvisid toiduteemalised kalambuurid; kaasliikmeid ärgitasid reageerima ka ameti, inimsuhete ja (pop)kultuuri üle aasivad sõnamängud. Kommentaare kogunes ohtralt veel küsimuse vormis kalambuuride juurde, sest postituses sisalduv küsimus innustas lugejaid kommentaariks pakkuma sõnamängulisi vastuseid. (Harrik 2019: 48-60)

\section{Meediapõhine uudisfolkloor ja Igor Mangi juhtum KalambuuRis}

Päevakajaliste kalambuuride uurimisel toetusin ennekõike Trevor Blanki (2009) rahvaluulemääratlusele, mis võimaldab vaadelda peale suust suhu leviva pärimuse ka internetis levivat ainest. Blank peab folklooriks , üksikisikute ja nende kogukondade loomingulisuse erivormilisi ja koosmõjulisi väljendusi” (2009: 6) ehk rõhk on koos tegutsemisel, mitte ainuüksi keskkonnal, kus seda tehakse. Internetifolkloor on lai nähtus, mille teemadering hõlmab kõike maailmas leiduvat. Konkreetselt uudistest 
innustatud ainese uurimiseks võtsin appi kitsama uudisfolkloori (ingl newslore) mõiste. Russell Frank peab uudisfolkloori internetifolklooriga lähedaseks, ent mitte kattuvaks nähtuseks, mis „parodeerib, pilab ning kritiseerib salvavalt massimeediat” (Frank 2011:9).

2018. aasta märtsi postituste vaatlusel ilmnes, et uudisfolkloorsete kalambuuride keskmes on sageli mäng kellegi nimega. Argiuudistest lähtuvates sõnamängudes leitakse üldtuntud isikunimedele homonüüme (isikunime kokkulangevus mittenimega) või paronüüme (isikunime sarnasus mittenimega), asetades seeläbi nime uude, oma kandjat pilavasse konteksti. Pilatavate nimede valik on suhteliselt kitsas, sest nalja toimimiseks peab võimalikult suur hulk publikust jagama nalja autoriga ühiseid teadmisi. KalambuuRi liikmete seas on hästi tuntud ja kasutusel vaid maailma suurriikide parasjagu võimul olevate juhtide, aga ka Eestis parasjagu ametis oleva peaministri ja teiste kohalike tipp-poliitikute nimed. Uudissündmusi pilavate naljade vaatlusel selgus, et sõnadega mängima innustab pigem mõne uudise keelekasutus kui sisu. Nii võis juhtuda, et ühepalju kalambuure postitati nii suure meediasündmuse kui ka väikese kõlapinnaga, ent huvitavalt sõnastatud pealkirjaga uudise teemal. (Harrik 2019: 70-74)

Järgnevalt vaatlen Igor Mangi juhtumiga seotud uudisfolkloori, st kuidas ja mida KalambuuRi postitustes skandaalse juhtumiga seoses pilatakse või kritiseeritakse. Giselinde Kuipers (2002), kes on uurinud üleilmsetele katastroofiuudistele - nagu World Trade Centeri tornide langemine või printsess Diana surm - järgnenud temaatilist huumorit, osutab, et skandaalse uudise mõjul lähevad esmalt liikvele sõnamängulised naljad, mis aja möödudes asenduvad uudise sisuliste asjaolude üle aasivate naljadega (Kuipers 2002: 453). Püüan järgnevalt tuvastada, kuivõrd selline muster Mangi juhtumile järgnenud postitustes paika peab. Russell Frank (2011: 167-168) osutab muuhulgas, et kuulsuste - nagu printsess Diana või Michael Jacksoni - elu ülemäärane, emotsionaalses võtmes kajastamine muutub inimestele tüütavaks ning huvi asemel kutsub uudistetulv neis esile kahjurõõmu. Meediatarbijad väljendavad oma küllastumust naljadega, mis ei pila enam pelgalt skandaalseid sündmusi, vaid kogu viimastega kaasnevat meediakära. Niisiis on uudisfolkloori üks funktsioone esindada rahvalikku meediakriitikat. Kuna Mangi juhtumi tuules avaldati arvukalt jätku-uudiseid, arvamuslugusid ning isegi meelelahutuslikke nõuandeartikleid, jälgin sellele skandaalile järgnenud postituste juures ka meediakriitika ilminguid.

Uudis tähetark Igor Mangist jõudis laiema avalikkuse ette 9. mail 2018 kell 20.00 eetris olnud rahvusringhäälingu telekanali ETV saates „Pealtnägija” (Kärmas, Gavronski 2018). Uudislugu paljastas, kuidas aastakümneid meedias - ennekõike Maalehe aastahoroskoobi koostajana - tuntust kogunud astroloog Igor Mang oma vastuvõttudel naisi seksuaalselt ahistab. Loo ajendas ahistamist kogenud naiste pöördumine „Pealtnägija” poole ning üks naine kirjeldas saates endaga juhtunut. Naise sõnul oli tal tähetargaga juhuslik kohtumine tänaval, mille käigus mees ta Kadrioru pargis kasvava tammepuu tüveõõnsusesse raviseansile kutsus, ent teda tervendamise asemel sobimatult katsus. Kontrollimaks samalaadsete lugude tõesust, korraldas „Pealtnägija” toimetus eksperimendi, mille käigus kaks noort naist 
läksid anonüümselt ning salajase diktofoniga varustatult Mangi juurde n-ö seansile. Kummagi katseisiku kohtumine astroloogiga viimase sotsiaalkorteris kulges sarnase stsenaariumi järgi. Esmalt kiitles Mang varasemate kuulsate klientidega ning kiitis toonast Tallinna linnapead Edgar Savisaart, kellelt oli korteri saanud. Seejärel koostas mees kummalegi naisele isikliku horoskoobi, millest luges mõlemal juhul välja, et naisele sobiksid paljud seksuaalsed partnerid ning et naine armub peagi astroloogi. Järgmiseks luges tähetark kummagi naise käejoontest välja, et nende tšakrad on kinni, ning asus enda sõnul tšakraid avama. Selle jaoks kustutas ta tule, palus kummalgi naisel silmitseda aknale riputatud mandalat ning asus käte abil raviprotseduuri sooritama. Viimast kirjeldavad mõlemad naised aga rindade ja jalgevahe sobimatu katsumisena. Esimesele katseisikule pani Mang protseduuri järel mängima Elvis Presley muusika ning palus naisel tantsida. Kohtumise lõpus kasseeris tähetark kummaltki naiselt 70 eurot. Uudislugu lõppes toimetuse telefonikõnega Mangile endale, mille käigus mees eitas igasugust ebasündsat puudutamist ning kirjeldas juhtunut vaid kallistamisena. (Kärmas, Gavronski 2018)

Kõnealust uudist nimetati skandaaliks juba samal õhtul Postimehe veebiportaali pealkirjas „„,Pealtnägija” korraldas Igor Mangi ahistamisskandaali paljastamiseks eksperimendi: „ta krabas mind sõna otseses mõttes jalge vahelt””' (Pealtnägija” korraldas... 2018). Uudise paisumisest sensatsiooniks annavad tunnistust järgnenud päevadel ilmunud jätku-uudised. 10. mail avaldati näiteks ERR-i uudisteportaalis uudis Mangi pikaajalise koostöö lõppemisest Maalehega (Mäekivi 2018) ning teadaanne mehe suhtes algatatud väärteomenetlusest (Politsei alustas... 2018). Postimehe seltskonnauudiste rubriigi Elu24.ee veergudel vormiti uudiseks (Joa 2018) 10. mail „Pealtnägija” Facebooki-lehel avaldatud postitus mitmetest teistest naistest, kes vastukajana saatelõigule teavitasid saate toimetust oma sarnastest ebameeldivatest kogemustest Mangiga. Elu24.ee ammutas juhtunust ühtlasi ainest poolpilavas võtmes artikliks „Mangi skandaali tuules: kuidas ja kust ikkagi avada naiste tšakraid?” (2018). Uudise üle võeti kummagi uudisteportaali arvamusrubriikideski sõna. Postimehes ilmusid näiteks 11. mail „Dagmar Lamp: esoteerikust ahistajas pole midagi koomilist” (Lamp 2018) ning 12. mail Taavi Minniku „Mangi tumedam pool” (Minnik 2018), ERR-i arvamusrubriigis aga 14. mail „Rain Kooli: Mang on liiga lihtne süüdlane” (Kooli 2018) ning 17. mail „Urmas Vadi: Ebareaalne Mang” (Vadi 2018).

Sedavõrd rohke meediakajastusega uudis innustas KalambuuRi liikmeid postitama kokku 32 selleteemalist sõnamängu. Vaid ühe erandiga olid kõigi nende autorid meessoost või vähemalt registreerunud mehenimega Facebooki kasutajaks. Ainus naissoost kasutaja postitatud sõnamäng (vt näidet 1) pole aga originaallooming: nali pärineb teisest Facebooki lühivormigrupist „Tähelepanekuid elust enesest” ning selle autor jääb teadmata. Selline sooline jaotumine sobitub KalambuuRi liikmeskonna üldise käitumismustriga, mille järgi mehed postitavadki kordades rohkem. (Harrik 2019: 45)

(1) Tõeline mees avab täna õhtul pudelite asemel hoopis oma naise tšakrad. - AV (n), 12. V, 14.34 . 
Ajaliselt esimene skandaalist innustatud kalambuur (näide 2) postitati enne „Pealtnägija” eetrisse minekut arvatavasti saadet tutvustava uudislõigu (Kärmas, Gavronski 2018) põhjal ning samal õhtul lisandus sellele vaid kaks temaatilist nalja (näited 3 ja 4).

(2) Mangumine sai täna uue tähenduse - MJ (m), 9. V, 19.38.

(3) tähetark ja numbriloll - JJ (m), 9. V, 21.49.

(4) astraalpervert - LK (m), 9. V, 22.08.

Juhtunu üle naljatamine sai KalambuuRis suure hoo sisse alles järgmisel päeval, 10. mail, kella kaheksa ja viie vahel. Kõnealuses ajavahemikus (vt diagrammi 1) postitati juhtunu teemal 14 sõnamängu, kusjuures umbes pooled tehti kella ühe ja kolme vahel ehk lõunapausi ajal ja järel. Siingi klapib postitamismuster minu magistritöös välja selgitatud üldise rühmaliikmete käitumisega (vt Harrik 2019: 43-44).

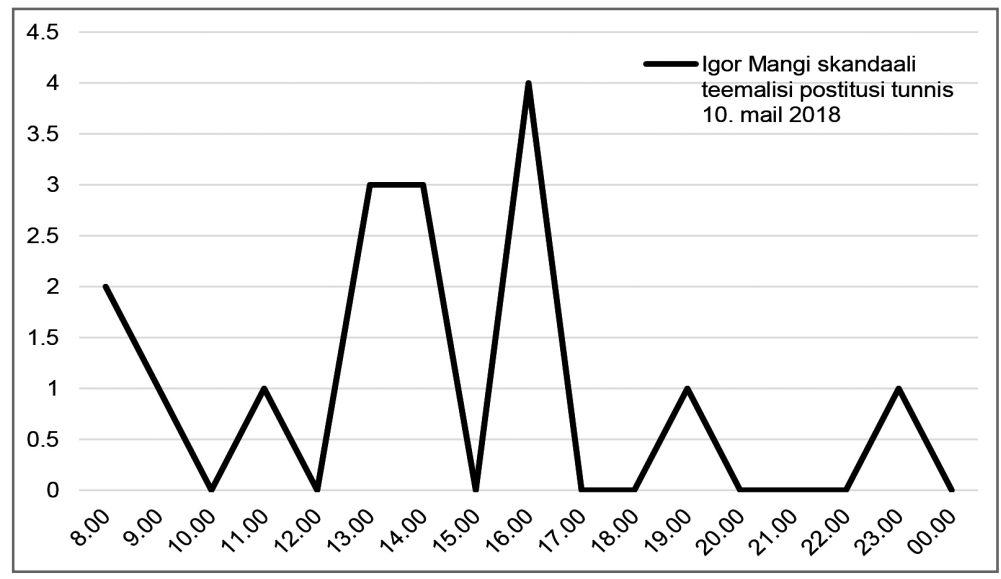

Diagramm 1. Igor Mangi skandaali teemalised postitused KalambuuRis 10. mail 2018 tunnikaupa.

10. mai temaatiliste naljade (näited 5-18) kohta kehtib Kuipersi (2002: 453) tähelepanek sõnamänguliste naljade kiiremast tekkest võrreldes sisu üle aasivate naljatekstidega, sest peamiseks ühisjooneks neis kalambuurides osutus mäng Igor Mangi perekonnanimega. Enamasti leitakse sellele paronüüme: mäng(ima) (näited $8,12,15,17,18)$, mang(uma) (näited 5 ja 6), kalambuuri kontekstis töötab paronüümina ka vang(la) (näide 20). Näites 13 kasutatakse ära nime Mang homonüümset kokkulangevust sõnaga kubermang, misjuures nalja tuum peitub hoopis selles, et kubermang omakorda langeb osaliselt kokku sõnaga kube. Näidetes 14, 16 ja 17 asetatakse Mang aga mõnes potentsiaalselt paljudele rühmaliikmetele tuttavas kultuuritekstis mingi teise sõna asemele, kusjuures nalja aluseks olnud laulutekst (näited 14 ja 17) või vanasõna (näide 16) on endiselt äratuntavad. Millegi muu kui Mangi nimega mängitakse vaid kolmes kalambuuris. Näites 7 on rõhk mitmetähenduslikkusel: sõna kepp ('pulk; seksuaalvahekord') ning väljend (millegi) peal väljas olema ('midagi tahtma; õues millelegi toetuma') on mõlemad polüseemsed. Näites 11 on 
pilkeobjektiks hoopis uudist levitanud uuriv-ajakirjanduslik telesaade „Pealtnägija”; naljas mainitakse ka saate toona peamist konkurenti Eesti tele-eetris, TV3-s (hiljem Kanal 2-s) jooksnud meelelahutuslikumat saadet „Kuuuurija”. Näide 10 on aga eriti tähelepanuväärne, sest tegemist pole niivõrd reaktsioonide pälvimiseks postitatud sõnamänguga, kuivõrd püüdega tekitada arutelu ning osutada rühma ühistegevusele. Lisaks Igor Mangi nimele leiab neist naljadest viiteid ka uudisest läbi käinud sisulistele detailidele, nagu sündmuspaik Kadriorg (näide 6) või ahistamisega seotud sünnituskoht (näide 8) ja puuõõnsus (näide 12).

(5) Igor Mangus seksi *rõõm - HP (m), 10. V, 8.14.

(6) Igor käis Kadrioru pargis Mangumas ... - RL (m), 10. V, 8.42.

(7) Need kaadrid tõestavad - Igor Mang on kepi peal väljas. - TS (m), 10. V, 9.09.

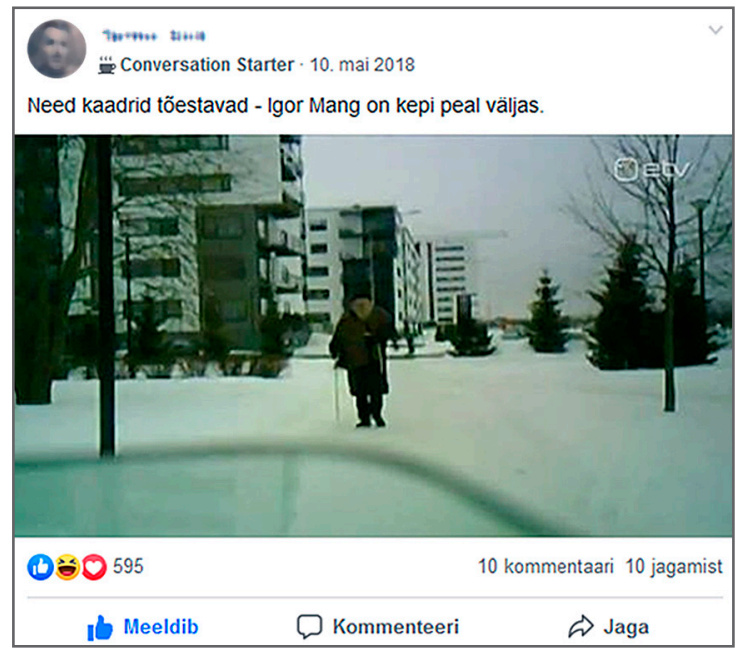

(8) Sünnituskohaga ei mangita! - AJ (m), 10. V, 11.52.

(9) Pisikese avaga kitsas ruum - mangla. - RM (m), 10. V, 13.09.

(10) Keegi võiks mõne Manginalja väänata. Mingi pool tundi juba pole olnud värsket. - TT (m), 10. V, 13.34.

(11) Kuuuurija uuris juba ammu täht tähetarka, paraku juhuslik pealtnägija avaldas loo enne. - EB (m), 10. V, 13.54.

(12) Puuõõnsus nüüdsest nimetada Mangulaks ,Mangumaania-Mangulik seks megalomaania, Mangustuma- tiirastunud vanamees, (jop)Manguntoonio, Mangumängud, Kolmas „silm” teab, - HP (m), 10. V, 14.05.

(13) Kubermang - JK (m), 10. V, 14.33.

(14) Meie Mangul kriimud silmad, istus metsas kännu otsas. Piip oli suus ja kepp oli käes, kutsus naisi pugema. Kes ei mõistnud pugeda, see sai tutist sugeda. - GA (m), 10. V, 14.34 .

(15) Mangumaa - DG (m), 10. V, 16.05.

(16) Mang tuleb plika ihu peale. - RR (m), 10. V, 16.16.

(17) Laul Ivo Linna repertuaarist „Kuidas läks sul see Mang?” - DG (m), 10. V, 16.18.

(18) Saku suurhallis All Star tähtede Mang - DG (m), 10. V, 16.28. 
Vaadeldud naljades kerkib esile meelelahutuslik ja kohati parastav toon. Näites 4 osutatakse ehk kõige karmimal toonil juhtunule kui perverssusele, sarnast mõtet kannavad ka seksuaalsusele ja ahistamisele rõhuvad näited 7, 8, 12-14 ja 16. Sagedasem on kahjurõõmus pilamine: näites 3 vihjatakse Mangile kui rumalale, näidetes 2, 5 ja 6 aga kui kellelegi, kes peab seksuaalvahekorda teistelt manguma. Eesti keele seletav sõnaraamat (EKSS 2009) pakub manguma tähendusteks 'pealeajavalt paluma, nuruma, nuiama, lunima' ehk Igor Mangi nähakse eemaletõukava isikuna, kellega vabatahtlikult vahekorda ei astuta ja kes peab seda lunima. Samalaadne on näide 7, kus rõhutakse tähetarga iharusele. Näited 15, 17 ja 18, kus Mangi ja mängu paronüümselt asendatakse, on aga meelelahutuslikumad ehk osutatakse, et ahistustegevus on tähetarga jaoks vaid omalaadne mäng.

Kahel järgmisel päeval Igor Mangi üle naljatamine vähenes. 11. mail postitati viis temaatilist kalambuuri, 12. mail kolm. Nagu esimesel päeval, esinevad teise uudisejärgse päeva kalambuurides (vt allpool näiteid 19-23) samad uudisega seotud märksõnad, nagu Kadriorg (näide 19) ja sünnituskoht (näide 22), aga pilke alla satuvad ka Mangi ametitegevusega seotud horoskoop (näide 20) ja tervendamine (näide 21). Seisukohad juhtunu osas korduvad samuti: astroloogi käitumist hinnatakse hirmutavaks (näide 20) ning perversseks (näide 21); taas on esindatud Mangi ja mängu sidumine (näide 22). Näitest 23 leiab aga esimesi märke teema ammendumisest: Mangi-teemat nimetatakse juba habemega naljaks ehk vananenuks.

(19) Valgus kõnnib kadriorus! - GA (m), 11. V, 10.32.

(20) horrorskoop - ML (m), 11. V, 11.39.

(21) Eda ei anna häbeneda, nüüd kui pervendaja Mang on mängust väljas. - AT (m),

11. V, 14.27.

(22) Sünnituskoht on manguasi - JO (m), 11. V, 14.59.

(23) Aitab kah, Mang on habemega nali. - MA (m), 11. V, 23.01.

Neljanda päeva ehk 12. mai esimene Mangi-teemaline postitus (vt näidet 24) on - nagu 11. mai viimanegi postitus - ühtaegu nali vahekorda manguva Mangi üle, ent samas soovitus sel teemal naljatamine lõpetada. Järgnevad kaks nalja tšakrate avamise teemal (näited 1 ja 25). Alates 13. maist jäävad naljad aga üha harvemaks (näited 26-30); viimane temaatiline nali pärineb 22. maist. Teemaderingi midagi uut ei lisandu: endiselt naljatatakse Mangi nime (näited 24, 26, 28), seksi mangumise (näide 24), puuõõnsusesse pugemise (näited 28 ja 29), horoskoopide (näide 29) ja tšakrate avamise (näide 30) teemadel. Ainus teist laadi kalambuur mängib kõnealuse skandaali jätku-uudise „Politsei kutsus Mangi välja” (2018) juures kohatud sõnavalikuga: pealkirjas esinevat väljendit välja kutsuma ('ametlikus korras aru andma kutsuma') tõlgendatakse polüseemselt tähenduses 'kohtingule kutsuma'. Näites 28 ilmneb taas rühma eneseregulatsioon: postitaja alustab nalja sõnadega No üks veel..., andes mõista, et tajub rühmaliikmena teema ammendumist, kuid soovib siiski oma nalja kaasliikmetega jagada. 
(24) Jätke see Mangumine! Aitab küll! - RV (m), 12. V, 9.19.

(25) Tšakrate asemel avab Mang edaspidi vaid makraid. - VV (m), 12. V, 22.46.

(26) Seisab nagu mangumatu tinasõdur - MO (m), 13. V, 1.20.

(27) Loodan, et ikka romantilisele õhtusöögile või kinoõhtule * mõtlik ${ }^{*}$ - AT (m), 15. V, 3.31.

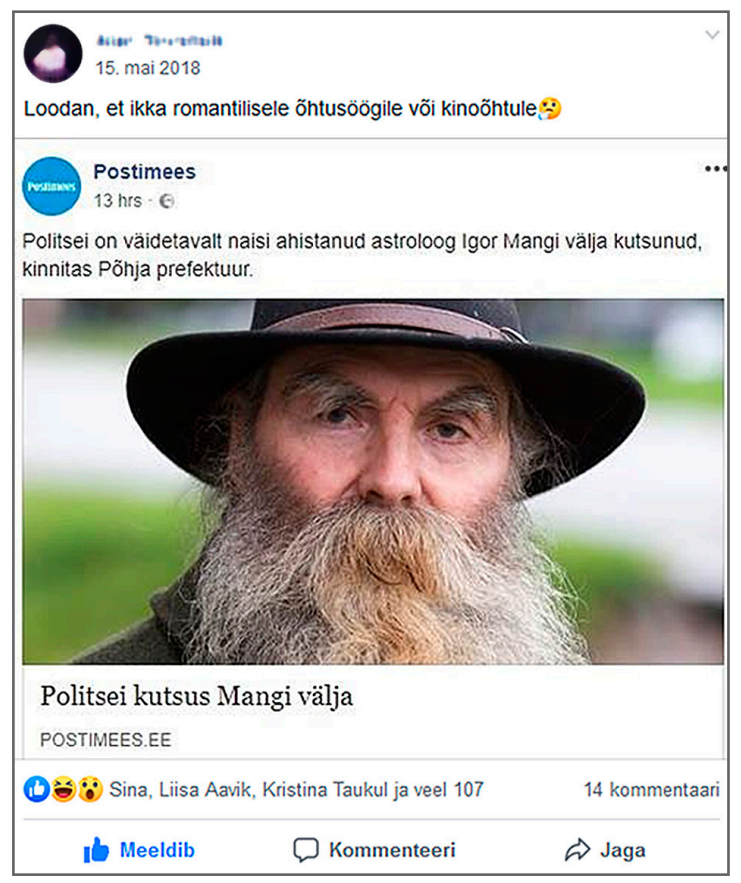

(28) No üks veel.... Kuidas nimetada kui sa tahad rahulikult puu sees olla ja saadad avaja ära aga tuleb ringiga tagasi? Bumermang - SEC (m), 19. V, 14.34.

(29) Hooruskoopide uskumisega võib praegusel ajal üsna puusse panna. - VV (m), 21. V, 23.33.

(30) Akvamang - aparaat veealusteks tšakratseremooniateks - EK (m), 22. V, 12.05.

Igor Mangi ahistamisskandaalile järgnenud postituste tulv KalambuuRi grupis peegeldab hästi digitaalselt leviva info kiirust ja emotsionaalset laetust. Skandaalile reageeriti juba seda kajastanud saate ajal, ent kuna uudis jõudis avalikkuse ette õhtutundidel, saabus juhtunu üle naljatamise haripunkt järgmise päeva ennelõunal. Internetis on uudise eluiga lühike, sest juhtum hakkas aktuaalsust kaotama juba teisel uudisejärgsel päeval. Postitustes mängiti algul peamiselt Igor Mangi perekonnanime kujuga, hiljem üha rohkem juhtumi muudegi asjaoludega. Kuna skandaal seisnes tuntud tähetarga ootamatult ilmsiks tulnud lähenemiskatsetes oma noortele naissoost klientidele, väljendasid naljad ka KalambuuRi liikmete hinnanguid juhtunule. Astroloogi käitumist tauniti kui perversset ja sobimatut, postituste toon oli kohati isegi parastav. Naljades kohtas pilkeid ka uusvaimsuse ja alternatiivmeditsiini ning nende teemade kajastamise kohta meedias. 


\section{Kokkuvõte}

Igor Mangi juhtumi vastuvõtt KalambuuRis näitas, kuidas internetis ringlevas folkloorses aineses saavad kriitika osaliseks nii kõmu-uudis ise kui ka uudise kõmuliseks paisutanud meedia. Kalambuurides pilati ennekõike skandaali keskmesse sattunud astroloogi ennast küll tema perekonnanimele paronüüme leides, küll tema tegevustele osutades. Samas naljatati ka uudist kajastanud „Pealtnägija” saate ning skandaali arvukate jätku-uudiste üle. Arvestades, et Mangi koostada oli lugejarekordeid püstitav Maalehe aastahoroskoop, pälvisid kriitikat ka astroloogia ning selle kajastamine.

Vaadeldud temaatilistest postitustest 30 olid sõnalised, ainult kaks postitust kasutasid visuaalset osist mõnest Mangiga seotud uudisest. Kuna KalambuuRi meessoost liikmed postitavad kolm korda enam kui naissoost liikmed, polnud üllatav, et ka Mangi juhtumit kommenteerinud naljade autorid olid pea eranditult mehed. Ajaliselt kulges postituste tulv võrreldavat rada pidi Giselinde Kuipersi (2002) kirjeldatud katastroofinaljade elutsükliga. Kuigi kõik vaadeldud tekstid on sõnamängulised naljad, postitati uudisele järgnenud päeval enim Igor Mangi nimekuju ehk sündmuse pinnapealse asjaoluga seotud nalju; järgnenud päevadel nihkus kalambuuride kese skandaali sisulistele aspektidele, nagu sündmuspaik (Kadriorg, puuõõnsus) ja tegevus (tervendamine, tšakrate avamine, ahistamine) või muudele juhtunuga seotud detailidele (horoskoop, sünnituskoht). Jälgida võis ka pärimusrühma tunnetuslikku eneseregulatsiooni: juba teise uudisele järgnenud päeva õhtuks tajuti teema ammendumist. Järgnenud päevadel ammendatuse tunne süvenes, ning kuigi meedias ilmuvad jätku-uudised hoidsid mõnel määral juhtumi aktuaalsust üleval, vaibus skandaali üle naljatamine lõplikult kaks nädalat pärast uudise eetris olemist. Skandaali järelkajas tulid esile KalambuuRi liikmete hinnangud juhtunule. Astroloogi füüsilisi lähenemiskatseid noortele naistele nähti perverssete ja sobimatutena; toona 68-aastast Igor Mangi ennast aga ebameeldiva mehena, kellega vabatahtlikult seksuaalsuhetesse ei astuta. Kalambuuridest võis välja lugeda kahjurõõmugi, et tuntud astroloogi karjäär ootamatu lõpu leidis.

KalambuuR on ennekõike keelemängude postitamiseks mõeldud grupp, milles on aktiivsematest kasutajatest argise postitamise käigus välja kujunenud väiksem pärimusrühm. Selle liikmeskonnale pakub sõnadega mängimine erinevaid rühmatunnet loovaid suhtlusvõimalusi, nende seas võimalust maailmas toimuva kohta arvamust avaldada ning mõttekaaslasi leida. Nii tulevadki KalambuuRi liikmetele sageli just lõunalauas pähe mõtted, kuidas mõne parasjagu aktuaalse uudise või tuntud inimese üle natuke nalja heita, ning lõunapausilt arvuti juurde naasnuna vormistavad nad oma mõtted kaasliikmete heakskiitu ootavaks postituseks. Tõsiasi, et need postitavad liikmed on enamjaolt mehed, osutab aga veebihuumori soolisele kallutatusele. Igor Mangi juhtum näitas, et seksuaalsuse ning sugudevaheliste suhete üle julgevad ja soovivad KalambuuRi näitel nalja teha vaid mehed. Vääriks edasist uurimist, milline on postitajate sooline jaotumine teistes sotsiaalmeedia huumorigruppides ning kas mujalgi sõltub naljataja sugu samal määral pilkealusest teemast. 
Artikli valmimist on toetanud Euroopa Liit Euroopa Regionaalarengu Fondi kaudu (Eesti-uuringute Tippkeskus).

\section{VEEBIALLIKAD}

Eesti värssmõistatused. Koost Piret Voolaid, 2015. http://www.folklore.ee/Varssmoistatused Facebook: Tähelepanekuid elust enesest. https://www.facebook.com/elustenesest/ Facebook: KalambuuR. https://www.facebook.com/groups/kalambuur/

\section{KIRJANDUS}

Attardo, Salvatore 1994. Linguistic Theories of Humor. (Humor Research 1.) Toim Victor Raskin, Mahadev Apte. Berlin-New York: Mouton de Gruyter.

Attardo, Salvatore; Raskin, Victor 1991. Script theory revis(it)ed: joke similarity and joke representation model. - HUMOR. International Journal of Humor Research, kd 4, nr 3-4, lk 293-347.

Baran, Anneli 2010. Fraseologismide rollist Eesti koolinoorte keelekasutuses 2007. aasta koolipärimuse kogumisvõistluse põhjal. - Tulnukad ja internetilapsed. Uurimusi tänapäeva laste- ja noortekultuurist. (Tänapäeva folkloorist 8.) Toim Eda Kalmre. Tartu: EKM Teaduskirjastus, lk 95-124.

Baran, Anneli 2011. On the role of phraseologisms in the Estonian online media. - Prace naukowo-dydaktyczne Państwowej Wyższej Szkoły Zawodowej w Krośnie 55. (Papers on Language, Culture and Literature 3.) Toim Alicja Witalisz. Krosno: Państwowa Wyższa Szkoła Zawodowa w Krośnie, lk 105-114.

Baran, Anneli 2012. Visuaalne huumor internetis. - Mäetagused, nr 52, lk 123-140.

Baran, Anneli 2013. On the role of visualisation in understanding phraseologisms on the example of commercials. - Folklore. Electronic Journal of Folklore, nr 53, lk 47-72.

Baran, Anneli 2014. Visualiseerimise rollist fraseologismi mõistmisel reklaamide näitel. Maailm ja multitasking. (Tänapäeva folkloorist 10.) Koost ja toim Mare Kõiva. Tartu: EKM Teaduskirjastus, $1 \mathrm{k}$ 77-106.

Blank, Trevor J. 2009. Introduction. Toward a conceptual framework for the study of folklore and the Internet. - Folklore and the Internet: Vernacular Expression in a Digital World. (All USU Press Publications 35.) Toim Trevor J. Blank. Louisville: University Press of Colorado, lk 1-20.

EKSS 2009 = Eesti keele seletav sõnaraamat. Toim Margit Langemets, Mai Tiits, Tiia Valdre, Leidi Veskis, Ülle Viks, Piret Voll. Tallinn: Eesti Keele Sihtasutus. http://www.eki.ee/dict/ ekss/ekss.html (28. X 2019).

Examples of Puns in Literature. - YourDictionary. https://examples.yourdictionary.com/ examples-of-puns-in-literature.html (28. X 2019).

Frank, Russell 2011. Newslore: Contemporary Folklore on the Internet. Jackson: University Press of Mississippi.

Harrik, Airika 2019. Folkloristlik vaade KalambuuRile Facebookis. Magistritöö. Käsikiri Tartu Ülikooli eesti ja võrdleva rahvaluule osakonnas.

Itskok, A. 1998. Algus on otsas. Keelevigureid. Tallinn: Maalehe Raamat. 
Joa, Vahur 2018. „Pealtnägija” toob esile järgmised Igor Mangi ohvrid: ta nühkis end minu vastu ja ma tundsin, et tal on erektsioon. - Postimees. Elu24, 10. V. https://elu24.postimees.ee/4486233/pealtnagija-toob-esile-jargmised-igor-mangi-ohvrid-ta-nuhkisend-minu-vastu-ja-ma-tundsin-et-tal-on-erektsioon (28. X 2019).

Juur, Mart; Konnula, Margus; Lomp, Oliver; Vilms, Keiti 2019. Poeetiliselt korrektne. Toim K. Vilms. Tallinn: MTÜ Poeetiliselt korrektne.

Kooli, Rain 2018. Rain Kooli: Mang on liiga lihtne süüdlane. - ERR. Arvamus, 14. V. https:// www.err.ee/831297/rain-kooli-mang-on-liiga-lihtne-suudlane (28. X 2019).

Krikmann, Arvo 1997. Sissevaateid folkloori lühivormidesse I. Põhimõisteid, žanrisuhteid, üldprobleeme. Tartu: Tartu Ülikooli Kirjastus.

Kuipers, Giselinde 2002. Media culture and Internet disaster jokes: bin Laden and the attack on the World Trade Center. - European Journal of Cultural Studies, kd 5, nr 4, lk 450-470.

Kärmas, Mihkel; Gavronski, Anna 2018. „Pealtnägija”: mitu naist süüdistavad Igor Mangi seksuaalses ahistamises. - ERR. Eesti, 9. V. https://www.err.ee/830003/pealtnagija-mitunaist-suudistavad-igor-mangi-seksuaalses-ahistamises (28. X 2019).

Lamp, Dagmar 2018. Dagmar Lamp: esoteerikust ahistajas pole mitte midagi koomilist. Postimees. Sõbranna, 11. V. https://sobranna.postimees.ee/4486779/dagmar-lamp-esoteerikust-ahistajas-pole-mitte-midagi-koomilist (28. X 2019).

Mangi skandaali tuules: kust ja kuidas ikkagi avada naiste tšakraid? - Postimees. Elu24, 10. V 2018. https://elu24.postimees.ee/4486146/mangi-skandaali-tuules-kuidas-ja-kustikkagi-avada-naiste-tsakraid (28. X 2019).

Minnik, Taavi 2018. Mangi tumedam pool. - Postimees. Arvamus, 12. V. https://arvamus. postimees.ee/4487044/mangi-tumedam-pool (28. X 2019).

Mäekivi, Mirjam 2018. Maaleht lõpetab koostöö Igor Mangiga. - ERR. Eesti 10. V. https:// www.err.ee/830238/maaleht-lopetab-koostoo-igor-mangiga (28. X 2019).

„Pealtnägija” korraldas Igor Mangi ahistamisskandaali paljastamiseks eksperimendi: „ta krabas mind sõna otseses mõttes jalge vahelt". - Postimees. Elu24, 9. V 2018. https:// elu24.postimees.ee/4485836/pealtnagija-korraldas-igor-mangi-ahistamisskandaali-paljastamiseks-eksperimendi-ta-krabas-mind-sona-otseses-mottes-jalge-vahelt (28. X 2019).

Politsei alustas Igor Mangi ahistamisskandaali asjus menetlust. - ERR. Eesti, 10. V 2018. https://www.err.ee/830304/politsei-alustas-igor-mangi-ahistamisskandaali-asjus-menetlust (28. X 2019).

Politsei kutsus Mangi välja. - Postimees, 14. V 2018.

Vadi, Urmas 2018. Urmas Vadi: Ebareaalne Mang. - ERR. Arvamus, 17. V. https://www.err. ee/832215/urmas-vadi-ebareaalne-mang (28. X 2019).

Veskioja, Hanna (toim) 2018. Verbaarium. Pikri kalambuure aastaist 1985-2001. Tallinn: Tänapäev.

Viilup, Kaspar 2018. ERR.ee video: HeadRead kalambuuriõhtu. - ERR. Kirjandus, 25. V. https://kultuur.err.ee/834328/err-ee-video-headread-kalambuuriohtu (28. X 2019).

Vilms, Keiti 2017. @keitivilms. Tallinn: Tänapäev.

Voolaid, Piret 2015. Lapsesuufolkloor lingvistilise huumoriteooria vaateväljas. Suulistel ütlustel põhinev kirjalik traditsioon. - Keel ja Kirjandus, nr 12, lk 841-858. 
Voolaid, Piret; Kalle Voolaid 2020. Eesti spordikommentaatorite ütlused rahvahuumori allikana. - Keel ja Kirjandus, nr 1-2, lk 44-61.

Whedbee, J. William 1998. The Bible and the Comic Vision. Cambridge: Cambridge University Press.

Ülviste, Andrus 2012. Poogen, kopp ja siiber. Tallinn: Kadmirell.

Airika Harrik (snd 1995), MA, Eesti Kirjandusmuuseumi Eesti Rahvaluule Arhiivi assistent (Vanemuise 42, 51003 Tartu), airikaharrik@gmail.com

\section{Reception of scandalous news in the Facebook group KalambuuR}

Keywords: folkloristics, minor genres, humour, newslore, social media

The article takes a closer look at some topical puns posted in the Facebook group KalambuuR, which is an Estonian group created for posting wordplays. The analysis is based on 32 topical puns from May 2018, which are related to a harassment scandal involving the famous Estonian astrologer Igor Mang. The scandal emerged when the investigative TV programme Pealtnägija (Eyewitness) uncovered that during his healing sessions Igor Mang had been harassing his female clients for years.

When commenting on the aforementioned scandal, KalambuuR members reacted fast, posting numerous topical puns the same evening and the following day, but got tired of the topic within a week. At first, most puns made fun of Igor Mang's (sur)name, later moving on to more specific details (e.g. places, activities, astrology related terms) of the scandal. In their posts, members criticized Mang for having acted perversely, describing him as sexually unpleasant and showing content about the end of his astrologer's career. Topical posts worked also as a form of folk mediacriticism: some puns were aimed at numerous news items that followed the original scandal.

Overall, KalambuuR is a virtual community originally created for the sole purpose of posting puns, where active members have found new possibilities of communication via posting. For them KalambuuR is a place to make their voice heard and meet other like-minded individuals. A typical active KalambuuR member is a man at work who comes up with a pun regarding contemporary news events during his lunch break and posts his pun in the afternoon for other members to react to.

Airika Harrik (b. 1995), MA, Estonian Literary Museum, Estonian Folklore Archives, Assistant (Vanemuise 42, 51003 Tartu), airikaharrik@gmail.com 